\title{
Characterization of Polycapillary X-Ray Semilenses with SEM/EDX
}

\author{
V. Rackwitz,* M. Procop,** and V.-D. Hodoroaba* \\ * BAM Federal Institute for Materials Research and Testing, Division VI.4 Surface Technologies, \\ 12200 Berlin, Germany \\ ** IFG Institute for Scientific Instruments, 12489 Berlin, Germany
}

Polycapillary X-ray optics is more and more utilized in X-ray fluorescence (XRF) analysis. Polycapillary optics is an ensemble of glass capillaries, which transport the radiation by means of total reflection on their inner surface. The X-ray polycapillary optics referred to in this paper is socalled semilenses. While in $\mu-X R F$ instruments full lenses are used to focus the radiation of a microfocus X-ray tube onto the specimen, semilenses are applied to focus the parallel beam of synchrotron radiation. They are also used in collecting mode to collect and parallelize a beam, e.g. in front of an energy dispersive X-ray detector in $3 \mathrm{D}-\mu \mathrm{XRF}$ [1] or to increase the low energy efficiency of such detectors [2].

The aim of this work is to define a methodology for specification of polycapillary X-ray semilenses for quality assurance at the manufacturers. The most relevant parameters considered are the full width of half maximum (FWHM) of the acceptance area, the focal distance as well as the transmission [3-5]. The acceptance area, defined only in the collecting direction of the semilens, is the area in its focal plane from which emitted X-ray photons are collected and parallelized.

For the characterization of the parameters above a novel procedure involving SEM/EDS (scanning electron microscope / energy dispersive X-ray spectrometer) instrumentation has been employed. We take advantage of the very small excitation volume induced by the electron beam in a SEM compared to the acceptance area of the X-ray semilens. The lens was adjusted onto the front of the EDS in collecting mode by means of an adapter (Fig. 1). The specimen selected is a test material containing $\mathrm{C}, \mathrm{Al}, \mathrm{Mn}, \mathrm{Cu}$ and $\mathrm{Zr}$ [6]. The electron beam at $10 \mathrm{kV}$ and $30 \mathrm{kV}$ has been scanned over the specimen surface, so that the acceptance area (see Fig. 2 for $5.9 \mathrm{keV}$ ) and the transmission are extracted from the resulting spectral maps of characteristic line intensities. The energy dependence of both parameters can be evaluated as well.

\section{References}

[1] B. Kanngießer et al., Nucl. Instr. and Meth. in Phys. Res. B 211 (2003) 259.

[2] www.parallaxray.com/eds.html

[3] T. Wolff et al., J. Anal. At. Spectrom. 24 (2009) 669.

[4] A. Bjeoumikhov et al., X-Ray Spectrom. 32 (2003) 172.

[5] N. Gao and I. Y. Ponomarev, X-Ray Spectrom. 32 (2003) 186.

[6] www.webshop.bam.de, ("Reference materials"/“"Test materials"/“EDS-TM001") 
[7] Many thanks are due to Mrs. S. Benemann for performing the measurements. The work is part of the project "MNPQ-Transfer" 23/07. V. Rackwitz acknowledges the support of the "BAMDoktorandenprogramm".

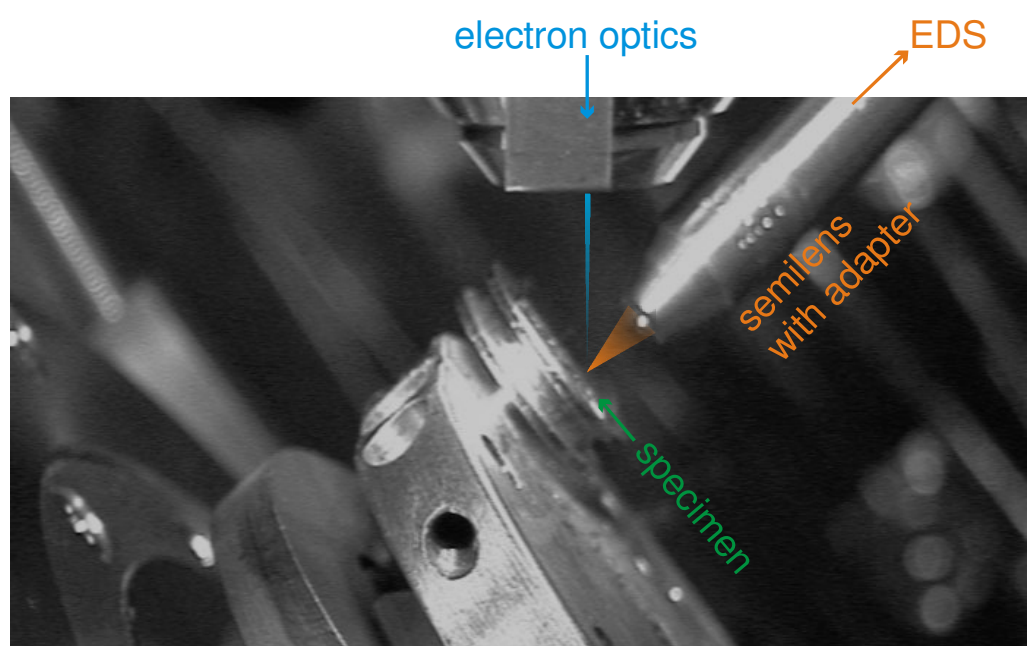

FIG. 1 Image of the measurement geometry in the SEM: adapter containing the polycapillary X-ray semilens onto the front of the EDS. The specimen was tilted, so that the normal of the specimen surface becomes identical with the lens-detector axis.

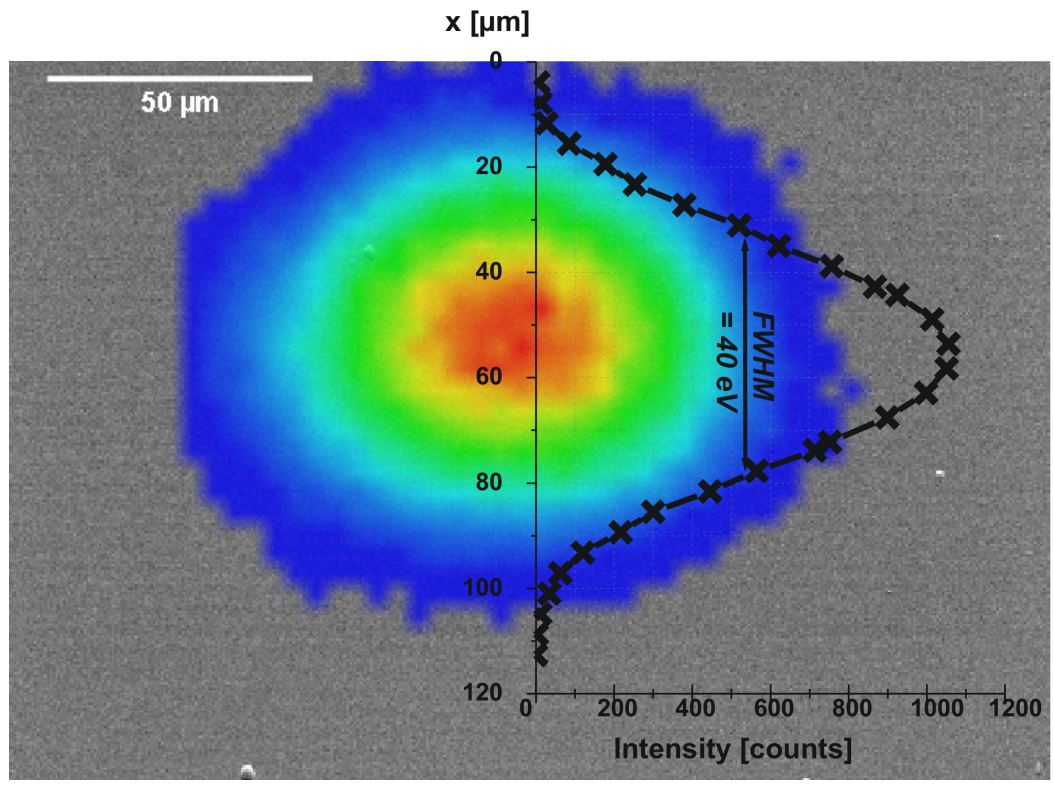

FIG. 2. The map of $\mathrm{Mn} \mathrm{K} \alpha$ line intensity revealing the acceptance area of the semilens at $5.9 \mathrm{keV}$ (in thermal colors). Also shown is a linescan extracted from the map for the determination of the FWHM. 